\title{
BLOCO 6
}

\section{COMUNICAÇÃO SOCIAL EM SAÚDE E EDUCAÇÃO}

1 - Informação, Educação e Comunicação em Programas de Atenção à Crianças de 0 - 6 Anos

2 - Comunicação Social em Saúde e Educação—-Relato de Expenência 


\title{
INFORMAÇÃO, EDUCAÇÃO E \\ COMUNICAÇÃO EM PROGRAMAS \\ DE ATENÇAS A CRIANÇAS DE 0 - 6 ANOS
}

\author{
INFORMATION, EDUCATION ET \\ COMMUNICATION DANS LES PROGRAMMES \\ D’ASSISTANCE AUX ENFANTS DE 0 - 6 ANS
}

David Boianovsky ${ }^{1}$

BOIANOVSKY, D. - Afana ão, Educação e Comunicação em Programas de Atenção à Crianças de 0 - 6 anos. Rev. Bras. Cresc. Des. Hum III 11: São Paulo, 1993.

\section{RESUMO}

Uma atitude esclarecida pode ser o melhor remédio para melhorar o nível de vida das populações com baixo poder aquisitivo. Recebendo informações básicas, em linguagem acessível, os agentes comunit rios, os pais e familiares saberão como proceder para proteger a comunidade, principalmente as crianças de 0 - 6 anos, que necessitam de cuidados especiais. O recurso do marketing social, que utiliza as técnicas da mfdia e do marketing, pode ser aplicado para se conseguir uma mudança de comportamento nos integrantes dessas comunidades, que passam a se beneficiar da informação. Mas esse programa depende de serviços básicos: recursos humanos e uma rede de saúde pública capacitada

\section{RÉSUMÉ}

Une altitude éclairée peut être le meilleur moyen d'améliorer lo niveau de vie des populations les plus démunies. En recevant des inforrnations de base, en langage accessible, les agentes communautaires, les parente et leurs familles sauront comment proceder afin de proteger la communauté, surtout lãs enfants de 0 à 6 anã, qui demandent une attention particulière. Lerecours au marketing social, qui utilise les techniques de média et du marketing, permet d'obtenir un changement de comportement des membros de la communauté, ayant ainsi te bénéfice de l'information. Ce progra^Tnme dépend toutefois des services de base: personnel et réseau de santé publique compétents.

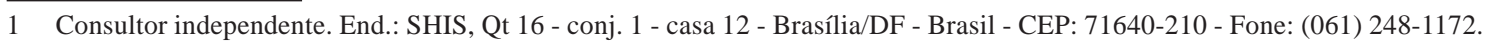


Informações básicas e uma atitude esclarecida por parte dos agentes comunitárias, pais, familiares e público em geral podem reduzir drasticamente as taxas de mortalidade e até promover um desenvolvimento mais harmônico das crianças pobres de 0 a 6 anos. Portanto, é preciso uma mudança de comportamcnto dos "trabalhadores de saúde”, conceito que abrange todos aqueles que podem contribuir para o bemestar da criança, notadamente os que vivem na própria comunidade.

Nos serviços de saúde, o principal elemento de mudanças é o "agente comunitário", quando ele existe. Esse trabalhador primário é membro da própria comunidade, que o escolhe para representá-la. Para atuar como agente de saúde, ele recebe treinamento básico e informações. Nas populações, a mulher, pelo contato direto e cuidados que dispensa à criança, é potencialmente o maior agente de mudanças.

Graade parte dos problemas de saúde do grupo de 0 a 6 anos depende dos serviços básicos executados pclos agentes treinados e membros das comunidades, que são levados a par icipar ativamente pelas próprias necessidades e também pela motivação para uma mudança de comportamento. Já são bem conhecidas muitas das medidas primárias que melhoram as condições de vida das populações rurais e setores urbanos pobres.

São informações sobre ammazenamento de alimentos, proteção de mananciais, distribuição e tratamento de água não encanada, manutenção das moradias, etc. Esses serviços básicos dependem de comportamento solidário e espfrito participativo da comunidade. (1) Um eficiente programa de informação, educação e comunicação social (IEC) tempor objetivo justamente isso: formar agentes comunitários capazes de estimular, de forma bem direcionada, novos comportamentos e atitudes, e sensibilizar a comunidade, para que fique receptiva a esse $\mathrm{t}^{\wedge} \mathrm{Mbalho}$.

Entre os componentes mais criticos e efetivos dos serviços básicos se encontram os que a familia e a comunidade podem fazer em favor da saúde e do desenvolvimento das crianças de 0 a 6 anos. Isso inclui o aleitamento matemo exclusivo nos primeiros seis meses, a mobilização para vacinação e até reivindicações e açoes relativas a saneamento básico e serviços de saúde.

É um conjunto de atitudes, comportamentos e práticas que pretendemos seja adotado para elevar as condições de vida e de saúde de um determinado grupo não beneficiado pelas polfticas sociais básicas. Essa mudança social, no entanto, só será duradoura se o serviço de saúde estiver ao alcance da comunidade, como referência, e os agentes comunitários, quando houver, forem treinados e periodicamente supervisionados.

\section{Marketing social}

Segundo KOTLER e ROBERTO, marketing social é uma estratégia de mudança de comportamento que combina elementos de abordagem tradicional com os recursos das técnicas de comunicação e marketing (2). GRIFFITHS e BERG acrescentam que é indispensável identificar a percepção da população sobre os assuntos que se pretende abordar, e responder a essa percepção (3).

Especificamente para saúde, BOIANOVSKY, FICHTNER e MAMEDE propõem que, além de adotar os conceitos anteriores, o material educativo deve ser eficiente no aspecto afetivo e cognitivo do público alvo. Só assim promoverá uma mudança racional permanente, em vez de ser apenas induzida e transitória, como a publicidade.

É indispensável que o material de IEC inclua infommação cientifica pertinente (a história natural de uma enfermidade, por exemplo), com texto e ilustrações dirigidos ao aspecto cognitivo do público-alvo. De maneira que esse público passe a compreender a questão abordada e os comportamentos, atitudes e práticas que se recomendam, incorporandoos como um novo conhecimento. Por outro lado, não deve ser relegado o aspecto afetivo, que, em saúde, exerce influencia crítica. E por essa ^Mzão que se deve trabalhar nos aspectos afetivo-cognitivo $(4,5)$.

\section{Abordagem transcultural}

O estudo da percepção do público sobre o assunto a ser abordado é um passo crftico para o planejamento e a execução de programas de IEC. As variáveis que constitucm essa percepção são tipicamente culturais, motivo pelo qual este estudo é, na maior parte, antropológico. Outros aspectos culturais devem ser levados emconta,mas o importante é que os responsáveis pelo IEC estejam dispostos a aprender com o público-alvo antes mesmo de começar a educá-lo.

Muitas vezes, o aprendizado a respeito desse modo cognitivo-afetivo do público cria a necessidade de "fabular" a verdade científica e assim torná-la compreenslvel (ó). MONTEIRO LOBATO (7) mostrava, com uma lente, como bichinhos parecidos com minhocas penetravam no pé do Jeca Tatu, provocando uma debilitante doença. Compreendendo, desta forma, uma parte decisiva da história natural da doença, Jeca Tatu acatou a recomcndação de usar botinas para proteger-se. Transformou-se num saudável e próspero fazendeiro, que fazia até as galinhas e os porcos calçarem as providenciais botinas.

Informações básicas e uma atitude esclarecida por parte dos agentes comunitárias, pais, familiares e público em geral podem reduzir dras- 
ticamente as taxas de mortalidade e até promover um desenvolvimento mais harmônico das crianças pobres de 0 a 6 anos. Portanto, é preciso uma mudança de comportamcnto dos "trabalhadores de saúde”, conceito que abrange todos aqueles que podem contribuir para o bemestar da criança, notadamente os que vivem na própria comunidade.

Nos serviços de saúde, o principal elemento de mudanças é o “agente comunitário”, quando ele existe. Esse trabalhador primário é membro da própria comunidade, que o escolhe para representá-la. Para atuar como agente de saúde, ele recebe treinamento básico e informações. Nas populações, a mulher, pelo contato direto e cuidados que dispensa à criança, é potencialmente o maior agente de mudanças.

Graade parte dos problemas de saúde do grupo de 0 a 6 anos depende dos serviços básicos executados pclos agentes treinados e membros das comunidades, que são levados a par icipar ativamente pelas próprias necessidades e também pela motivação para uma mudança de comportamento. Já são bem conhecidas muitas das medidas primárias que melhoram as condições de vida das populações rurais e setores urbanos pobres.

São informações sobre ammazenamento de alimentos, proteção de mananciais, distribuição e tratamento de água não encanada, manutenção das moradias, etc. Esses serviços básicos dependem de comportamento solidário e espfrito participativo da comunidade. (1) Um eficiente programa de informação, educação e comunicação social (IEC) tempor objetivo justamente isso: formar agentes comunitários capazes de estimular, de forma bem direcionada, novos comportamentos e atitudes, e sensibilizar a comunidade, para que fique receptiva a esse trabalho.

Entre os componentes mais críticos e efetivos dos serviços básicos se encontram os que a familia e a comunidade podem fazer em favor da saúde e do desenvolvimento das crianças de 0 a 6 anos. Isso inclui o aleitamento materno exclusivo nos primeiros seis meses, a mobilização para vacinação e até reivindicações e açoes relativas a saneamento básico e serviços de saúde.

É um conjunto de atitudes, comportamentos e práticas que pretendemos seja adotado para elevar as condições de vida e de saúde de um determinado grupo não beneficiado pelas polfticas sociais básicas. Essa mudança social, no entanto, s6 será du^Mdou^ ${ }^{\wedge}$ se o serviço de saúde estiver ao alcance da comunidade, como referência, e os agentes comunitários, quando houver, forem treinados e periodicamente supenisionados.

\section{Marketing social}

Segundo KOTLER e ROBERTO, marketing social é uma estratégia de mudança de comportamento que combina elementos de abordagem tradicional com os recursos das técnicas de comunicação e marketing (2). GRIFFITHS e BERG acrescentam que é indispensável identificar a percepção da população sobre os assuntos que se pretende abordar, e responder a essa percepção (3).

Especificamente para saúde, BOIANOVSKY, FICHTNER e MAMEDE propõem que, além de adotar os conceitos anteriores, 0 material educativo devc ser eficiente no aspecto afetivo e cognitivo do público alvo. Só assim promoverá uma mudança racional permanente, em vez de ser apenas induzida e transitória, como a publicidade.

É indispensável que o material de IEC inclua infommação cientifica pertinente (a história natural de uma enfermidade, por exemplo), com texto e ilustrações dirigidos ao aspecto cognitivo do público-alvo. De maneira que esse público passe a compreender a questão abordada e os comportamentos, atitudes e práticas que se recomendam, incorporandoos como um novo conhecimento. Por outro lado, não deve ser relegado o aspecto afetivo, que, em saúde, exerce influencia crítica. E por essa razão que se deve trabalhar nos aspectos afetivo-cognitivo $(4,5)$.

\section{Abordagem transcultural}

O estudo da percepção do público sobre o assunto a ser abordado é um passo crftico para o planejamento e a execução de programas de IEC. As variáveis que constitucm essa percepção são tipicamente culturais, motivo pelo qual este estudo é, na maior parte, antropológico. Outros aspectos culturais devem ser levados emconta,mas o importante é que os responsáveis pelo IEC estejam dispostos a aprender com o público-alvo antes mesmo de começar a educá-lo.

Muitas vezes, o aprendizado a respeito desse modo cognitivo-afetivo do público cria a necessidade de "fabular" a verdade cientlfica e assim torná-la compreenslvel (6). MONTEIRO LOBATO (7) mostrava, com uma lente, como bichinhos parecidos com minhocas penetravam no pé do Jeca Tatu, provocando uma debilitante doença. Compreendendo, desta forma, uma parte decisiva da história natural da doença, Jeca Tatu acatou a recomcndação de usar botinas paraproteger-se. Transformou-se numsaudável e próspero fazendeiro, que fazia até as galinhas e os porcos calçarem as providenciais botinas. 


\section{Meios de comunicação}

A escolha dos meios de comunicação seguirá critérios que deverão consideraras condições locais, o custo, o acesso dapopulação, aeficiência do programa de IEC, o contato direto com o grupo a ser atingido e até a utilização dos meios de comunicação de massa.(8) Independentemente do peso que cada meio venha a ter na decisão, é fundamental que o programa de IEC abranja várias opções de recursos, aplicando-se um planejamento para que tais meios sejam reforçadores e até complementares entre si.

No Brasil, as mensagens transmitidas pelo rádio e TV são eficientes,mas unilaterais,istoé, não admitem diálogo. Os álbuns seriados,com os quais o Ministéiro da Saúde/COSMI tem feito interessante experiência, ilustram eficientemente uma exposição feita pelo educador ou treinador. As cartilhas, os manuais e outros materiais impressos são eficientes meios de informação, por is so, devem estar sempre disponíveis para os pais e trabalhadores de saúde. Qualquer que seja o IEC para saúde de crianças de 0 a 6 anos, deve ter a utilização de multimeios como regra geral.

Não é raro uma campanha de mudança ou mobilização falhar porque o público respondeu, mas não encontrou serviços em condições de atender à demanda provocada. Durante uma campa-

\section{REFERENCIAS BIBLIOGRÁFICAS}

01. UNICEF. Uma Estratégia para os Serviços Básicos, livrete, mato, 1980.

02. KOTLER, P. e ROBERTO, E.L. Marketing Social, Ed. Campus, ^1992.

03. GRIFFITHS, M. e BERG, A. Comunicação Pessoal.

04.BOIANOVSKY, D. Projeto de Controle do Paludismo: Componentes IEC para estimular a adoção de proteção individual contra o mosquito e a eliminação de pequenos criadouros em ambiente comunitário e doméstico. Minis- nha de vacinação, observei, no interior do Nordeste, fortes sentimentos de frustração porque os centros e postos de saúde locais não dispunham de vacina em quantidade suficiente.

É fundamental também que os recursos humanos, de todos os níveis, estejam preparados e treinados para apoiar e promover as mudanças desejadas. O agente comunitário é peça chave, mas o programa de IEC não deve ficar limitado a ele. Um componente especialmente elaborado para os profissionais de saúde, de níveis médio e superior, deve constar do programa de IEC.

Recomenda-se que a comunicação social em programas de atenção a crianças de 0 a 6 anos seja desenvolvida com as seguintes normas: adoção de marketing social que utilize os conceitos acima expostos; definição como grupo alvo prioritário os trabalhadores primários em saúde e educação, especialmente os agentes comunitárias; desenvolvimento de materiais para as comunidades, especialmente os pais, com destaque para as mães; desenvolvimento de materiais para os profissionais de saúde (mas não se admite a limitação do programa aos agentes).

É necessário ainda assegurar-se de que a rede de saúde esteja capacitada para atender as crianças de 0 a 6 anos. Aliás, esse é um pré-requisito indispensável para se planejar e pôr em execução um programa de IEC social para saúde.

tério da Saúde de São Tomé e Príncipe e Banco Mundial, 1991.

05.BOLINOVSKY, D.; FICHTNER, M.; MAMEDE, M. Projeto Treinamento de Lideres Comunitários, CNBB/Pastoral da Criança e UNICEF, 1992 (Video-tapes e álbuns seriados).

06.LLOSA, V.; S l ll, R. Conversas com Vargas Llosa, Editora Brasiliense, 1986.

07.LOBATO, M. História do Jeca Tatu, Almanaque do Biotônico Fontoura, publicado e distribuído nas décadas de 30 e 40.

08. WILLIAMS, G. e cols. Todos pela Saúde, livrete publicado pela UNICEF, 1989. 